from an examination of the changes of satellite orbits (leading to what may turn out to be a rather optimistic claim that "the general features of the air density distribution between about 180 and $700 \mathrm{~km}$ have now become well established").

In all, tho volumo contains a comprehensive account of observations and studies made during 1961 (except that only a little Russian work is included and that refers to the International Geophysical Year). Almost all the papers are in English with a Russian summary. Since practically everything has been published elsewhere it is particularly to be regretted that nothing is reported of the discussion which followed many of the papers.

R. Frith

\section{THE ART OF PAPER ELECTROPHORESIS}

\section{Hochspannungselektrophorese ihre Anwendungsmog- lichkeiten für Biochemische und Klinisch-chemische Trennprobleme}

By Dr. Med. Roman Clotten, Dr. Med. Annemarie Clotten. Pp. xv +556. (Stuttgart: Georg Thieme Verlag, 1962.) DM.98

$\mathrm{E}$

LECTROPHORESIS on rigid substrates such as moistened filter paper has become one of the more important methods for the identification and separation of compounds, rivalling chromatographic methods. This is not because the technique in itself is more versatile, there only being a limited number of $p \mathrm{H}$ values which can be used profitably, even in the presence of complexing agents, such as borate or sulphite, but because it is rapid and because it permits a fairly ready interpretation to be made of the nature of the compounds which are being investigated, or, alternatively, a confident prediction of the possible behaviour of unknown compounds.

Rapidity, of course, means the utilization of high voltages, or more properly high-voltage gradients, and this in turn involves the real danger of electrocution, which is not stressed in this text-book, and also the problems of the dissipation of heat and of the expense of the apparatus, both of which increase out of proportion to the voltage. The dissipation of heat is indeed a major problem, and of the two current solutions the authors prefer contact cooling by solids to cooling by immiscible liquids, a choice which is probably to be commended both because of the danger of fire and of the toxicity of some of the fluids used for cooling, but which has to be weighed against other factors such as compactness and general convenience.

An increase in voltage is not only associated with a speed of separation of small molecules which is actually somewhat greater than the voltage increase, largely because of diffusion effects, but it has also become associated with laboratory prestige, possibly because of the aura of danger accompanying high voltages, and this seems to have become a motivating influence with some workers.

Clotten and Clotten have written their excellent textbook with what is undoubtedly a background of considerable experience, largely of the clinical type, and they have endeavoured to make a comprehensive gift of their technical skill to the reader, together with all the background information which they consider he should need. Indeed, they tabulate buffer mixtures, spray techniques, sizes and properties of filter papers, including, incidentally, useful tables of the residual ion-exchange behaviour of commonly used papers and other factors, some relevant, some not. They also describe hydrolysis, concentration and desalting techniques though they omit, when discussing the latter, a particularly important caution to remove those ions common both to the specimen and the buffer because of their relative lack of mobility on subsequent electrophoresis, a phenomenon often puzzling to the inexperienced.

Another strange omission, particularly when one considers the thorough descriptions of eccentric elution techniques and other minutiæ, is the authors' failure to give any attention, apart from one specialized instance, to the problems of the power supplies needed and their construction. These constitute perhaps the most expensive items to purchase but are not at all difficult to build in the laboratory at reasonable prices, particularly now that silicon rectificrs are available.

The greater part of the text is given up to the analytical procedures to be adopted for the investigation of groups of compounds such as sugars, amines, etc., both from a qualitative and from a quantitative point of view, and these are excellently documented, and are illustrated by photographs, both in black-and-white and in colour, most of which are quite excellent, and if one may say so, a welcome change from the dreadful examples which one sees so often in print.

The book is excellently produced on good quality paper with an enormous bibliography and comprehensive index, and can be recommended to anyone interested in these methods who does not mind reading German and has 98 DM. to spend.

ROY MARKHAM

\section{HUMAN GENETICS}

\section{Outline of Human Genetics}

(Contemporary Science Books). By Prof. L. S. Penrose. Pp. xiv + 166. (London: Heinemann Educational Books, Ltd., 1963, second edition). $15 s$.

THIS book is precisely what it purports to be, namely an outline, but it has managed to cover a very wide field because of admirable economy in words. Through. out, Prof. Penrose deals with just those points which are of general interest and particularly topics about which people ignorant of genetics are always asking, for example, Is natural selection still operating in spite of civilization and medical advances?

He starts with a historical survey of the subjectthe story of Mr. Scott's colour-blindness in 1777 is most attractive-and then goes on to explain the essential differences between segregating and non-segregating characters. With respect to height (which has undergone such changes) it does, however, seem strange that the inheritors of Galton's laboratory cannot give us any more up-to-date estimate of the correlation coefficient between parent and child than that of 1890 .

In "Genes and Populations" good use is made of tables and diagrams, and Penrose clearly realizes the difficulty that a beginner has in understanding the Hardy-Weinberg law-and, arising out of it, such subjects as heterozygous advantage and the results of inbreeding. "Association and Linkage" is for the most part conventional, but the puzzles of the Rh system are interestingly presented and help to introduce readers to the idea of geographical variation in an inherited character.

Not only beginners would benefit from "Environment and Heredity" but also all those (and there are many of them) who accept the magic formula of 'identical twins brought up apart' as the solution to any naturenurture problem. After reading Penrose's survey they will think again.

Penrose delights in being the bane of the 'planners' in "Eugenics and Dysgenics" and is deliberately provocative with remarks such as the "heterozygous mongrel group can indeed be the gonetical backbone in a human popula. tion even if the members of this group may theoretically appear to be imperfect specimens".

Practically the only new feature in this second edition is one additional chapter ("Commentary") in which he 